\title{
Pseudoathetosis in the spectrum of alcoholic neurotoxicity: presentation and management
}

\author{
Hrishikesh B. Nachane ${ }^{1}$, Ajita S. Nayak ${ }^{2}$ \\ ${ }^{1}$ Assistant Professor, Department of Psychiatry, T.N.M.C. and B.Y.L. Nair Ch. Hospital, Mumbai \\ ${ }^{2}$ Professor and Head, Department of Psychiatry, K.E.M. Hospital and Seth G.S. Medical college, \\ Mumbai \\ Corresponding author: Hrishikesh Nachane \\ Email - hbnachane@gmail.com
}

\begin{abstract}
Pseudoathetosis, a proprioceptive abnormality, refers to a movement disorder consisting of involuntary, slow, writhing movements of the fingers. Although many causes for pseudoathetosis have been documented previously, such as multiple sclerosis, myelitis, leprosy, vitamin B12 deficiency, trauma, etc. it has not been previously described in a case of alcohol use disorder. A 50 years old man with chronic alcoholism presented to us with cognitive impairment, cerebellar signs and slow writhing movements of his fingers. Upon detailed investigations, no vitamin deficiency was detected. The patient was managed with a combination of nutritional supplementation, Memantine and Quetiapine, and had complete reversal of pseudoathetosis. The authors imply that pseudoathetosis can be a presentation of alcoholic neurotoxicity, co-occurring with cortico-cerebellar dysfunction, and can manifest irrespective of nutritional status of the patient.
\end{abstract}

Key words: Pseudoathetosis, alcohol, neurotoxicity

(Paper received $-5^{\text {th }}$ January 2020, Peer review completed $-20^{\text {th }}$ February 2020)

(Accepted $-28^{\text {th }}$ February 2020)

\section{INTRODUCTION}

With increase in alcohol consumption across India, there has been a steady rise in alcohol related complications [1]. The spectrum of alcoholic neurotoxicity is vast: covering dementia, Wernicke-Korsakoff syndrome, myelopathy to peripheral neuropathy. These conditions are not only challenging to diagnose, but downright difficult to treat [2]. Pseudoathetosis, a concept given by Dooling and Adams, refers to a movement disorder consisting of involuntary, writhing movements, which is clinically indistinguishable from athetosis [3]. Pseudoathetosis has been described in association with multiple sclerosis, myelitis, leprosy, stroke, vitamin B12 deficiency, spinal cord infarct, trauma, tumors, syringomyelia, and central pontine myelinolysis [4-6]. However, there is no documented report linking pseudoathetosis with alcoholism. We describe a case of pseudoathetosis in a patient of chronic alcoholism.

\section{CASE REPORT}

A 50 years old male patient presented with the chief complaints of sleep disturbances, irritability towards family members, difficulty in swallowing food, tremulousness of his hands and feet while walking since the past 2 months. The patient also complained of difficulty in speaking and was found to be stammering. Patient gave history of alcohol use in a dependent pattern for 30 years, drinking mainly country liquor (540 $\mathrm{ml} /$ day), which amounted to more than 120 units per week. On his physical and neurological 
examination, he was found to be irritable, having dysarthria, with impaired memory and intact orientation. He had positive cerebellar signs (ataxia, dysdiadochokinesia, past pointing and impaired coordination). When he stretched out his arms, his fingers showed involuntary, constant, slow writhing movements that became more prominent with eye closure. They disappeared during sleep. Patient had a positive Romberg's test. All his blood parameters which included a complete hemogram, serum electrolytes, blood sugars, folic acid, and vitamin B12 levels were within normal limits. His MRI brain had evidence of generalized cortico-cerebellar atrophy and no focal lesions or evidence of vascular insults were present. Our initial assessment was that of alcohol related cognitive impairment with alcohol related cerebellar degeneration and possibility of sensory involvement. Patient was treated with multivitamins, parenteral thiamine and Vitamin B12. Later on, Memantine $(5 \mathrm{mg})$ was added. Quetiapine was started for the sleep and behavioural disturbances, which was gradually up-titrated to $100 \mathrm{mg}$. Patient showed considerable improvement in his symptoms. His irritability reduced and cognition improved (though not to premorbid status). His gait was better and the writhing movements in his hands were seen to completely abate. Patient and relatives were psychoeducated regarding patient's illness, the hazards of alcohol use and the benefits of sobriety. Subsequent strategies for relapse prevention were charted, to be implemented on follow up.

\section{DISCUSSION}

Pseudoathetosis is caused by a failure of joint position sense (proprioception) and indicates disruption of the proprioceptive pathway, from nerve to parietal cortex [3]. Analogous to Romberg's sign, the abnormal posturing is most pronounced when the eyes are closed as visual inputs are unavailable to guide corrective movements. Despite of having a varied etiology, which includes both central and peripheral causes, to date no literature mentions pseudoathetosis in a case of alcoholism [4-6]. The present case showed consumption of alcohol in dependent pattern, leading to chronic neurological complications of alcohol: alcohol related cognitive impairment, cerebellar dysfunction and pseudoathetosis. Past literature on neurotoxic effects of alcohol has stated multiple mechanisms in its pathological process [7]. The two most popular reasons include nutritional deficiency and direct neurotoxic effects of alcohol and its metabolites (such as acetaldehyde) [7]. With absence of any vitamin deficiency, the authors suggest that alcohol could be directly responsible for its occurrence in the patient. Electrophysiological studies in peripheral nerve lesions have demonstrated that nerve conduction velocities in alcoholic patients are different from those seen in malnutrition related neuropathy, despite both presenting similar clinically [8-9]. These findings, similar to ours, suggest a direct toxic action of alcohol rather than nutritional deficiency acting as a mediator for neurotoxicity. As the patient had evidence of cerebral atrophy, it seems that a central cause for pseudoathetosis was more likely in him. Apart from these two factors, other mechanisms such as oxidative stress, involvement of protein kinases and caspases, role of spinal cord microglia and disturbances in glutamate pathway have also been suggested [7]. More central aetiologies could explain clustering of neurological complications and involvement of more than one system, as seen in our patient who had cognitive impairment and cerebellar dysfunction as well. Exploring the glutamate hypothesis suggests a pivotal role of metabotropic glutamate receptors (mGluRs) and N-methyl-D-aspartate (NMDA) receptors in neurotoxicity and nociception [10-11]. Narita and others reported that the pSer1303-NR2B subunit protein (subunit of NMDA receptor) in the spinal cord of rats was significantly increased following chronic ethanol treatment [12]. This could explain the success of Memantine in reversal of pseudoathetosis in our patient. Memantine has been tried for cognitive impairment related to alcohol and has been shown to lead to improvement in global cognition, quality of life and behavioural symptoms [13]. Memantine in higher doses has been shown to be effective in pain reduction in diabetic neuropathy as well [14]. Other treatment strategies deployed were abstinence, Quetiapine and nutritional supplementation. It is possible that a combination of these could have worked, and as such further research in this area is warranted.

The authors conclude that pseudoathetosis is a manifestation seen under the umbrella of alcoholic neurotoxicity and can exist without nutritional deficiencies. It correlates well with central neurodegeneration though it can have a peripheral cause. It is reversible akin to other neurological 
complications seen with alcohol with effective abstinence strategies and management of alcohol dependence. Memantine may play a role in management of pseudoathetosis as it does in other alcoholic neurotoxicities. It is thus necessary to effectively screen alcoholic patients for other possible complications, which may remain as yet undetected.

\section{REFERENCES}

1. Das SK, Balakrishnan V, Vasudevan DM. Alcohol: its health and social impact in India. Natl Med J India 2006;19(2):94-6.

2. Suzanne M, Kril JJ. Human alcohol-related neuropathology. Acta Neuropathol 2014;127(1):71-90.

3. Dooling EC, Adams RD. The pathological anatomy of posthemiplegic athetosis. Brain 1975;98(1):29-48.

4. Pujol J, Monells J, Tolosa E, Soler- Insa JM, Valls- Solé J. Pseudoathetosis in a patient with cervical myelitis: neurophysiologic and functional MRI studies. Mov Disord 2000;15(6):1288-93.

5. Ghika J, Bogousslavsky J. Spinal pseudoathetosis: a rare, forgotten syndrome, with a review of old and recent descriptions. Neurology 1997;49(2):432-7.

6. Misra UK, Kalita J, Mahadevan A, Shankar SK. Pseudoathetosis in a patient with leprosy. Mov Disord 2003;18(5):598-601.

7. Chopra K, Tiwari V. Alcoholic neuropathy: possible mechanisms and future treatment possibilities. Br J Clin Pharmacol 2012;73(3):348-62.

8. Behse F, Buchthal F. Alcoholic neuropathy: clinical, electrophysiological, and biopsy findings. Annals of Neurology 1977;2(2):95-110.

9. Koike H, Iijima M, Sugiura M, Mori K, Hattori N, Ito H, Hirayama M, Sobue G. Alcoholic neuropathy is clinicopathologically distinct from thiamine- deficiency neuropathy. Ann Neurol 2003;54(1):19-29.

10. Meller ST, Dykstra C, Gebhart GF. Acute thermal hyperalgesia in the rat is produced by activation of Nmethyl-D-aspartate receptors and protein kinase $C$ and production of nitric oxide. Neuroscience 1996;71(2):327-35.

11. Young MR, Fleetwood-Walker SM, Dickinson T, Blackburn-Munro G, Sparrow H, Birch PJ, Bountra C. Behavioural and electrophysiological evidence supporting a role for group I metabotropic glutamate receptors in the mediation of nociceptive inputs to the rat spinal cord. Brain Res 1997;777(1-2):161-9.

12. Narita M, Miyoshi K, Narita M, Suzuki T. Involvement of microglia in the ethanol-induced neuropathic pain-like state in the rat. Neurosci Lett 2007;414(1):21-5.

13. Cheon Y, Park J, Joe KH, Kim DJ. The effect of 12 -week open-label memantine treatment on cognitive function improvement in patients with alcohol-related dementia. Int $\mathrm{J}$ Neuropsychopharmacol 2008;11(7):971-83.

14. Pellegrino RG, Petit WA, Brazg R, Kirby LC, Rosenblatt S, Webb M, Schwartz S, Ahmann J, Ellison W, Gelblum J, Weinstein RL. Memantine in the treatment of diabetic peripheral neuropathy: A placebocontrolled phase IIB trial. Neurology 2000;54(7):82-4.

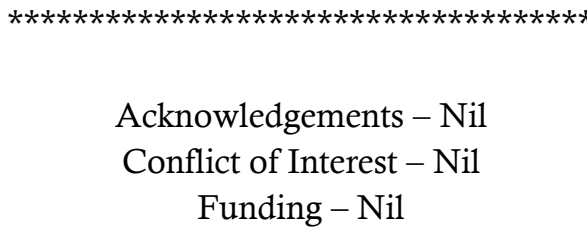

